\title{
AnneBot: Um Chatbot para Auxiliar no Processo de Ensino e Aprendizagem do Pensamento Computacional
}

\author{
Adrianne Veras de Almeida \\ Universidade Federal do Pará \\ Belém, Pará, Brasil \\ adrianne.almeida@icen.ufpa.br
}

\author{
Fabíola Pantoja Oliveira Araújo \\ Universidade Federal do Pará \\ Belém, Pará, Brasil \\ fpoliveira@ufpa.br
}

A evolução constante da tecnologia tem contribuído para inserção cada vez mais presente de dispositivos digitais utilizados como recursos educacionais para auxiliar alunos e professores. De acordo com dados publicados na literatura [1][2], investir em recursos e funcionalidades, principalmente educacionais, se tornou interessante uma vez que a familiarização e popularização da tecnologia está bem difundida com o público em geral. Nesse contexto, o aluno pode sentir necessidade em revisar o conteúdo visto em sala de aula para uma melhor assimilação, podendo utilizar os recursos digitais para auxiliar nesse processo de ensino e aprendizagem, no qual, um desses são os chatbots [3].

No trabalho [4] apresenta um Chatbot chamado de Astrobot desenvolvido por processamento de linguagem natural [PLN] e inteligência artificial para auxiliar no ensinoaprendizagem da disciplina de física. Dessa forma, a junção da tecnologia digital com a educação consegue ser apontada como um fator essencial para essa nova forma de aprender e compreender.

O objetivo deste trabalho é apresentar um chatbot chamado AnneBot ${ }^{1}$, desenvolvido utilizando o aplicativo mensageiro Telegram ${ }^{2}$, para auxiliar nas etapas de ensino-aprendizagem do PC [5][6] com alunos, esclarecendo dúvidas de forma inteligente.

Antes do desenvolvimento, foi realizado um levantamento bibliográfico das principais tecnologias e recursos para esse propósito. A linguagem de programação Python foi definida para o desenvolvimento da ferramenta, por ser uma linguagem simples e de fácil aprendizado.

Realizou-se o desenvolvimento da ferramenta através do ensino à máquina para a realização das conversas com o usuário, de maneira que foi inserido um conteúdo mais amplo, fazendo com que o "robô" aprendesse a responder e tirar dúvidas dos usuários. Exemplos de interações ${ }^{3}$ com a Annebot são: saudações - Oi, Olá, tudo bem?; apresentação de conteúdo sobre o PC - 0 que é Pensamento Computacional? Quais são os pilares do PC? 0 que é Pensamento de Automação? 0 que é Pensamento de Análise? 0 que é Pensamento da Abstração?; Como também, é possível perguntar sobre recomendações de livros, sites, artigos que trate sobre o tema. A AnneBot foi

Fica permitido ao(s) autor(es) ou a terceiros a reprodução ou distribuição, em parte ou no todo, do material extraído dessa obra, de forma verbatim, adaptada ou remixada, bem como a criação ou produção a partir do conteúdo dessa obra, para fins não comerciais, desde que sejam atribuídos os devidos créditos à criação original, sob os termos da licença CC BY-NC 4.0.

EduComp'21, Abril 26-30, 2021, Jataí, Goiás, Brasil (On-line)

(C)2021 Copyright mantido pelo(s) autor(es). Direitos de publicação licenciados à Sociedade Brasileira de Computação (SBC). integrado à plataforma do Telegram e para permitir a sua disponibilização no aplicativo mensageiro, permitindo assim que fosse acessado a qualquer momento.

Foi necessário disponibilizar os códigos no GitHub, uma plataforma de hospedagem de código-fonte e arquivos, e a plataforma Heroku também foi utilizada para realizar o deploy do Chatbot.

Este trabalho apresentou o desenvolvimento de um chatbot intitulado AnneBot para auxiliar os alunos no processo de ensino-aprendizagem do PC. Além disso, foram feitos testes iniciais para verificar se o chatbot estava funcionando corretamente, além de fazer uma análise a respeito do conteúdo introduzido no bot para verificar se o mesmo estava respondendo aos comandos digitados.

0 trabalho está em andamento, não foi possível fazer uso em um ambiente de ensino-aprendizagem pois não está ainda vinculado a nenhum conteúdo programático como por exemplo a lógica de programação. Para trabalhos futuros, pretende-se inovação a implementação utilizando técnicas de aprendizado de máquina para realizar o PLN. Além disto avaliar o rendimento e evolução dos alunos com a utilização da AnneBot para o aprendizado do PC, permitindo obter novas contribuições e possíveis limitações quanto à aplicação.

\section{AGRADECIMENTOS}

O presente trabalho foi realizado com apoio da Coordenação de Aperfeiçoamento de Pessoal de Nível Superior - Brasil (CAPES) e da Universidade Federal do Pará (UFPA).

\section{REFERÊNCIAS}

[1] Holotescu. C. 2016. Moocbuddy: a chatbot for personalized learning with moocs. In RoCHI-International Conference on Human-Computer Interaction, page 91 .

[2] Dehon, P., Silva, A., Inocêncio, A. C., Castro, C., Costa, H., and Júnior, P. P. 2018. Cvchatbot: Um chatbot para o aplicativo facebook Messenger integrado ao avamoodle. In Brazilian Symposium on Computers in Education (Simpósio Brasileiro de Informática na Educação-SBIE), volume 29, page 1623. DOI: http://dx.doi.org/10.5753/cbie.sbie.2018.1623

[3] Lucchesi, I. L., da Silva, A. R., Abreu, C., \& Tarouco, L. M. R. 2018. "Avaliação de um Chatbot no Contexto Educacional: Um Relato de Experiência com Metis" RENOTE, 16(1).DOI: https://doi.org/10.22456/1679-1916.85903.

[4] Dantas, A. C., Torres, H., de Paula Faria, I., Araújo, W., Guimarães, G., Guimarões, M., Almeida, V. A., Nascimento, M. Z. 2019, November). AstroBot: Um chatbot com inteligência artificial para auxiliar no processo de ensino e aprendizagem de física. In Anais dos Workshops do Congresso Brasileiro de

\footnotetext{
1 https://t.me/Anne_CompBot

$2 \mathrm{https://play.google.com/store/apps/details?id=org.telegram.messenger}$

3 https://drive.google.com/file/d/1VZcTGqoBLySaTCSLPa79MKZcKwIgZHn0/vi ew?usp=sharing
} 
EduComp'21, Abril 26-30, 2021, Jataí, Goiás, Brasil (On-line)

Informática na Educação (Vol. 8, No. 1, p. 1196). DOI: http://dx.doi.org/10.5753/cbie.wcbie.2019.1196.

[5] BRACKMANN, C. P. Desenvolvimento do pensamento computacional através de atividades desplugadas na educação básica. 2017. Tese.Programa de PósGraduação em Informática na Educação. Centro de Estudos Interdisciplinares em Novas Tecnologias na Educação, Universidade Federal do Rio Grande do Sul (UFRS), Porto Alegre.

[6] Wing, J. 2016. Pensamento Computacional- Um conjunto de atitudes e habilidades que todos, não só cientistas da computação, ficaram ansiosos para aprender e usar. Revista Brasileira de Ensino de Ciência e Tecnologia. 